\title{
Interfacial Mechanophore Activation Using Laser-Induced Stress Waves
} Jaeuk Sung, Maxwell J. Robb, Scott R. White, Jeffrey S. Moore, and Nancy R Sottos

J. Am. Chem. Soc., Just Accepted Manuscript • DOI: 10.1021/jacs.8b01427 • Publication Date (Web): 29 Mar 2018

Downloaded from http://pubs.acs.org on March 29, 2018

\section{Just Accepted}

"Just Accepted" manuscripts have been peer-reviewed and accepted for publication. They are posted online prior to technical editing, formatting for publication and author proofing. The American Chemical Society provides "Just Accepted" as a service to the research community to expedite the dissemination of scientific material as soon as possible after acceptance. "Just Accepted" manuscripts appear in full in PDF format accompanied by an HTML abstract. "Just Accepted" manuscripts have been fully peer reviewed, but should not be considered the official version of record. They are citable by the Digital Object Identifier (DOI®). "Just Accepted" is an optional service offered to authors. Therefore, the "Just Accepted" Web site may not include all articles that will be published in the journal. After a manuscript is technically edited and formatted, it will be removed from the "Just Accepted" Web site and published as an ASAP article. Note that technical editing may introduce minor changes to the manuscript text and/or graphics which could affect content, and all legal disclaimers and ethical guidelines that apply to the journal pertain. ACS cannot be held responsible for errors or consequences arising from the use of information contained in these "Just Accepted" manuscripts. 
Mechanical stress causes covalent bond scission in polymeric materials. In contrast to the typical mechanisms of failure such as homolytic bond cleavage, mechanically sensitive molecules called mechanophores are able to harness mechanical stress to achieve selective and productive chemical transformations. ${ }^{1}$ Mechanophores have been developed to access a range of forceinduced reactivity in polymers including fluorescence/color change,,$\frac{2}{-}$ catalyst formation, $\frac{3}{-}$ cross-linking, $\frac{4}{4}$ small molecule release,,$\frac{5}{}$ and even changes in electrical conductivity..-6 Typically, activation of covalently linked mechanophores in polymers is achieved using ultrasonication in solution, ${ }^{7}$ mechanical loading in bulk polymeric materials, $, \underline{2 b}, \underline{2 d}, \underline{8}$ or by single molecule force spectroscopy. ${ }^{2}$ Ultrasonication of polymer solutions provides a convenient and reliable method for screening mechanochemical activity, while single molecule force spectroscopy is able to characterize the forces required for activation of individual mechanophores in polymer chains. In bulk polymeric materials, tensile or shear force is applied to macroscale specimens to study the relationship between the activation stress/strain and mechanophore reactivity. In one example, $\underline{\text { b }}$ laser-induced stress waves were used to achieve high-strain-rate activation of mechanophores incorporated in bulk polymer films.

The potential for using mechanophores in coatings and composite materials has inspired recent efforts to investigate the mechanochemical activity of mechanophores localized at solid interfaces. For instance, the mechanochemical activation of a maleimide-anthracene (MA) mechanophore anchored between an inorganic nanoparticle surface and grafted polymer chains was achieved using ultrasonication in solution. ${ }^{10}$ Interfacial

mechanophore activation in this system was found to follow a similar behavior as chain-centered mechanophores, including first-order reaction kinetics and a minimum polymer chain length for mechanical activation. Additionally, the interfacial mechanochemical reaction of a diarylbibenzofuranone mechanophore in polymer-silica composite materials was accomplished under tension. ${ }^{11}$ The shear-induced activation of mechanophores located at interfaces has also been studied computationally. $\frac{12}{}$ Nevertheless, experimental methods for investigating mechanophore activation at solid interfaces remain limited, encouraging the development of new protocols to aid in the design and understanding of interfacial mechanochemical processes.

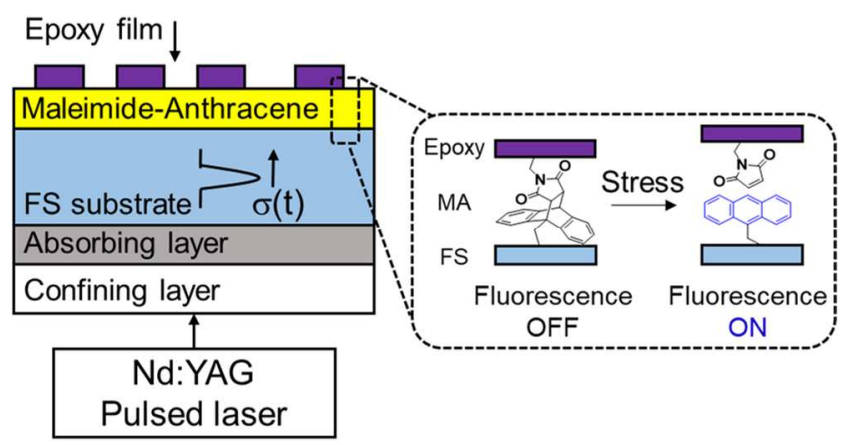

Figure 1. Interfacial mechanophore specimen design. Schematic representations of the experimental setup for generating laserinduced stress waves and mechanical activation of covalently anchored maleimide-anthracene (MA) mechanophores located at the epoxy-fused silica (FS) interface, which generates a fluorescent anthracene moiety bound to the silica surface with concurrent spallation of the epoxy film.

Herein, we demonstrate that laser-induced stress waves are capable of activating mechanophores located at solid interfaces. Moreover, this method provides a protocol for quantifying activation stress thresholds. Using this method, the activation of a MA mechanophore anchored at a solid interface is found to exhibit mechanochemical characteristics distinct from typical polymer systems, specifically a collective 'on-off' type activation response. The demonstration of laser-induced stress waves as a tool for mechanophore activation and characterization establishes a new platform for studying covalent mechanochemistry at solid materials interfaces and elucidates fundamental molecular 
processes that govern the mechanics of debonding and other interfacial phenomena.

Laser-induced stress waves have been used to generate large tensile stresses at thin film interfaces. ${ }^{13}$ As shown in Figure 1a, stress waves are generated by impingement of a Nd-YAG pulsed laser on an $\mathrm{Al}$ energy-absorbing layer. Rapid expansion of the $\mathrm{Al}$ layer and the presence of a sodium silicate confining layer causes a compressive stress wave, $\sigma(t)$, to propagate through the silica substrate towards the surface, where it reflects and generates a tensile stress at the interface between the substrate and the polymer thin film. Importantly, the magnitude of applied stress is systematically controlled by varying the laser fluence. The interface stress is determined by measuring the out-of-plane displacement of a calibration specimen with a Michelson interferometer to numerically calculate interface stress for a given laser fluence (see the supporting information (SI) for details). ${ }^{14}$ (a)

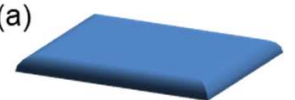

MA mechanophore functionalization

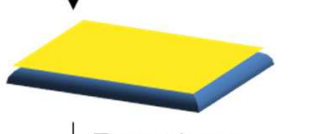

Epoxy layer deposition

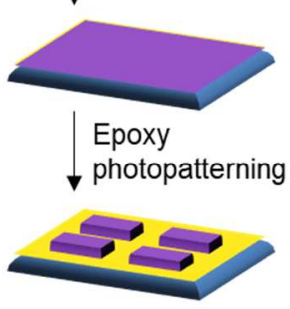

(b)

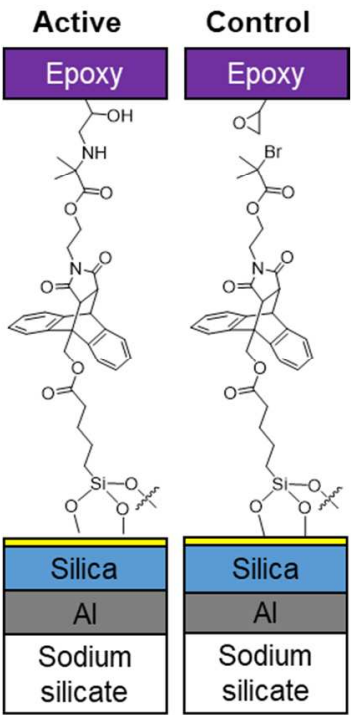

Figure 2. Interfacial mechanophore specimen preparation. (a) Fabrication process involving functionalization of a silica surface with a monolayer of the MA mechanophore followed by deposition and photo patterning of a $1 \mu \mathrm{m}$ thick epoxy top layer, and (b) the fused silica-epoxy interface comprising the MA mechanophore, which is covalently anchored to both surfaces in the active specimen. The control specimen does not contain a covalent linkage between the mechanophore and the epoxy layer.

The feasibility of mechanophore activation at a solid interface using laser-induced stress waves was investigated. A fused silica substrate was covalently functionalized with a maleimideanthracene (MA) mechanophore ${ }^{\underline{10}}$ and subsequently patterned with an epoxy polymer layer (Figure 2a). The active specimen contains a MA mechanophore with a terminal primary amine group, enabling covalent attachment to the patterned epoxy top layer (Figure 2b). In addition, control specimens were also prepared with a mechanophore that contains an alkyl bromide instead of an amino group, thus preventing covalent attachment to the epoxy film (Fig. 2b). Importantly, the MA mechanophore was anchored to the silica surface such that mechanochemical activation is expected to result in the formation of a substratebound and highly fluorescent anthracene moiety (see the SI for synthesis and specimen fabrication details).

Specimens were subjected to laser-induced stress waves with increasing interface stress and subsequently analyzed using optical and fluorescence microscopy (see the SI for experimental details). Mechanochemical activation of the MA mechanophore anchoring group is expected to occur only in regions containing covalently bonded epoxy films following spallation of the polymer from the specimen. For active specimens, complete spallation of the epoxy films from the substrate occurred at an interface stress greater than $149 \mathrm{MPa}$ (Figure 3a, see Figure S1 for all optical and fluorescence micrograph). Fluorescence micrographs indicate that spallation of the polymer films coincides with the activation of MA mechanophore anchoring groups (Figure 3b). A bright fluorescent pattern was observed in the same regions previously occupied by the epoxy films, indicating the spatially defined generation of anthracene on the surface. No fluorescence was observed prior to epoxy spallation, suggesting that partial mechanophore activation does not precede complete interfacial debonding of the polymer films. (a)

$149 \mathrm{MPa}$

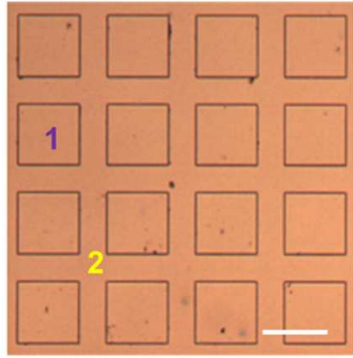

(b)

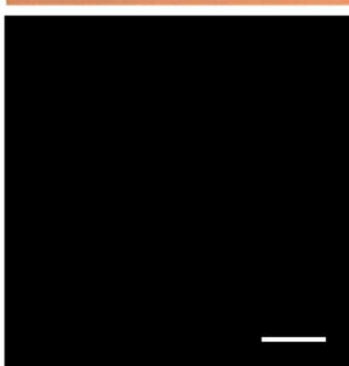

$163 \mathrm{MPa}$

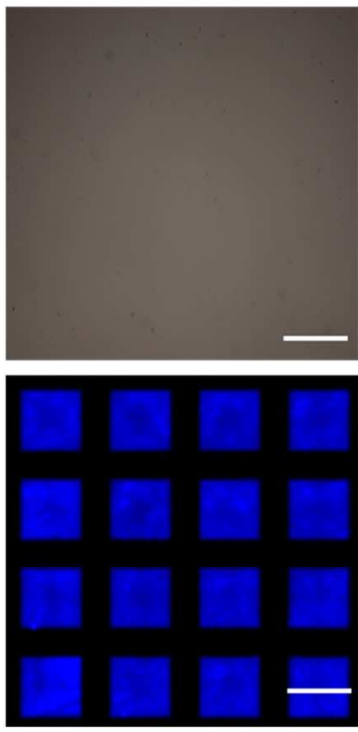

Scale bar $70 \mu \mathrm{m}$

Figure 3. Activation of interfacial MA mechanophores using laser-induced stress waves. (a) Optical (1-photopatterned epoxy, and 2-MA functionalized silica substrate) and (b) fluorescence micrographs of an active specimen following laser impingement with increasing laser intensity. At stress values $>149 \mathrm{MPa}$, the generation of a fluorescence pattern coincides with spallation of the epoxy films. The contrast of all images was increased $30 \%$ for clarity (original micrographs available in the SI).

In contrast to active specimens, spallation of the polymer films from control specimens occurred at a significantly lower interface stress (between 120 and $130 \mathrm{MPa}$ ) with no changes in fluorescence being detected (see Figure S2). A comparison of the fluorescence intensity between specimens with covalently and non-covalently bonded polymer layers after an applied stress of $163 \mathrm{MPa}$ is shown in Figure 4. The intensity profiles along 400 micron line segments of the corresponding fluorescence micrographs demonstrate that negligible mechanophore activation occurs in the control specimens while uniform fluorescence is observed across the specimens in regions of covalent polymer attachment. These results confirm that covalent attachment of the mechanophore at the interface is required for mechanophore activation. 


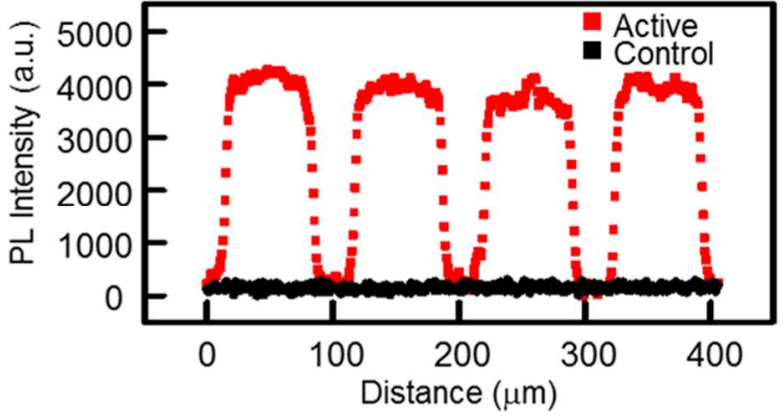

Figure 4. Comparison of the cross sectional fluorescence intensity profiles between active and control specimens after being subjected to an interface stress of $163 \mathrm{MPa}$.

Fluorescence intensity as a function of interface stress was measured using fluorescence microscopy to quantify the extent of mechanophore activation (Fig. 5). At each interface stress level, the average fluorescence intensity of a $400 \mu \mathrm{m}$ x $400 \mu \mathrm{m}$ area was calculated for specimens with covalent and non-covalent attachment of the polymer films to the mechanophorefunctionalized substrate. As described above, specimens with covalently anchored polymer films exhibited an abrupt increase in fluorescence intensity between 149 and $163 \mathrm{MPa}$ that coincided with film spallation. The fluorescence intensity plateaued following this apparent threshold activation stress, indicating that mechanophore activation occurs all at once and that no detectable mechanochemical transformations take place before or after epoxy film spallation. These results differ from the behavior of the MA mechanophore under alternative activation conditions, where a proportional increase in mechanophore activity with applied stress is typically observed. $\stackrel{7 d, 10,}{15}$ The collective activation behavior observed here is attributed to the monolithic structure of the crosslinked epoxy polymer compared to prior studies with mechanophores located in individual polymer chains, where bond breaking occurs in a stochastic process that is accelerated with increasing force. ${ }^{1,}, \underline{16}$ The fluorescence intensity achieved after mechanochemical activation using laser-induced stress waves reaches approximately $80 \%$ of that measured from an anthracene-functionalized reference specimen in the same square array (see SI for details). This relatively small discrepancy is likely due to incomplete bonding between the mechanophorefunctionalized substrate and the epoxy layer. The non-covalently bonded control specimens exhibited negligible fluorescence at all levels of applied interface stress, both before and after film spallation.

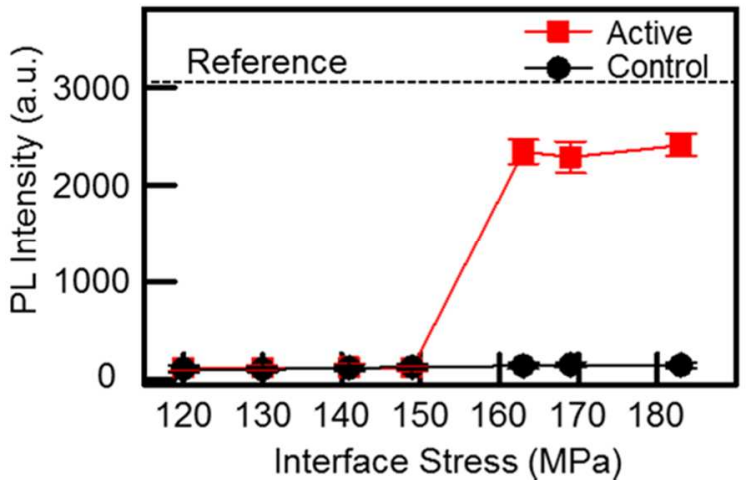

Figure 5. Average fluorescence intensity $(400 \mu \mathrm{m} \times 400 \mu \mathrm{m}$ region) after laser-induced stress wave generation as a function of interface stress for active and control specimens. Each data point represents the average of four measurements. As a reference, the dashed line represents the average fluorescence intensity of an anthracene-functionalized substrate with similar grafting density.

Additional surface analysis using Time-of-Flight Secondary Ion Mass Spectrometry (ToF-SIMS) imaging and X-ray photoelectron spectroscopy (XPS) was performed to further confirm activation of MA mechanophores with laser-induced stress waves. Active specimens were subjected to an interface stress of $163 \mathrm{MPa}$ and subsequently analyzed. ToF-SIMS imaging for the $\mathrm{CNO}^{-}$negative ion, originating from the maleimide fragment, ${ }^{17}$ illustrates the distribution of the intact MA adduct on the silica surface after laser impingement (Figure 6a). A low concentration of maleimide groups was detected within the square arrays where the epoxy films were initially deposited whereas a relatively high concentration was found in the interstitial regions. This result is consistent with the fluorescence measurements that showed selective mechanophore activation in locations of the covalently bonded epoxy films, which leads to the loss of the maleimide fragment via a retro Diels-Alder reaction upon spallation from the surface. Similarly, N 1s XPS spectra acquired in the same regions confirm the presence of the MA adduct in the interstitial regions with negligible signal detected within the square arrays (Figure $6 b$ ). The N 1s XPS signal peak at $401.2 \mathrm{eV}$ detected in the interstitial regions of the patterned film where no polymer was originally present agrees well with the expected binding energy for the MA adduct, indicating that it still remains after laser impingement and polymer spallation. The ToF-SIMS and $\mathrm{N} 1 \mathrm{~s}$ XPS measurements support the fluorescence microscopy results and indicate that, in the regions where the mechanophore is covalently bonded to the epoxy polymer, laser-induced stress waves in excess of the threshold activation stress cause the MA mechanophore to undergo a retro Diels-Alder reaction resulting in the generation of an anchored anthracene moiety and concomitant spallation of the polymer film.
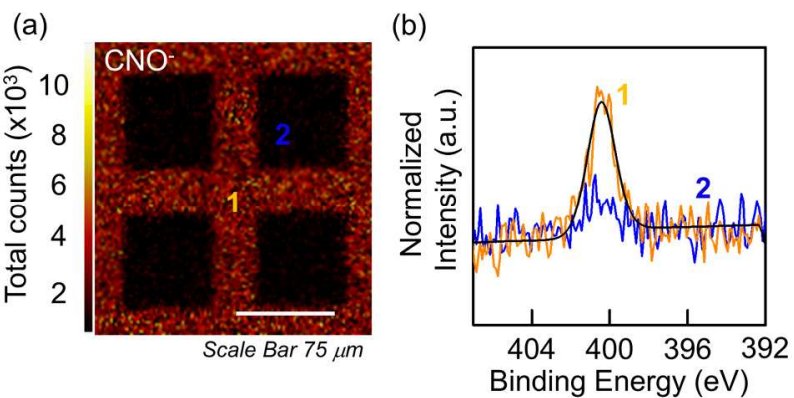

Figure 6. XPS and ToF-SIMS surface analysis of a covalently bonded specimen after laser impingement at $163 \mathrm{MPa}$. (a) ToFSIMS image for fragment $41.99 \mathrm{u}$ (CNO-) corresponding to the maleimide moiety. (b) N 1s XPS spectrum corresponding to the maleimide and primary amine groups in the MA mechanophore. Blue and orange traces correspond to the raw N 1s XPS signals inside and outside the square array, respectively. The black trace corresponds to a fit of the signal outside the square array.

In summary, we demonstrated that laser-induced stress waves are capable of activating MA mechanophores covalently anchored at a silica-polymer interface. The interface stress at the mechanophore functionalized interface was systematically increased by tuning the laser fluence. The measured threshold activation stress for the MA mechanophore was between 149 and $163 \mathrm{MPa}$. Covalent attachment of the mechanophore to both the silica and polymer surfaces at the silica-polymer interface was critical for mechanochemical activation, which occurred 
concurrently with polymer spallation from the surface. These findings were supported with fluorescence microscopy, XPS, and ToF-SIMS measurements. Mechanophore activation was not observed in specimens with a non-covalently anchored polymer film even after film spallation, which occurred at significantly lower interface stress compared to the covalently bonded specimens. More broadly, this research introduces a new technique for investigating covalent mechanochemistry at solid interfaces and expanding the fundamental understanding of molecular processes that underpin the mechanics of debonding and other interfacial phenomena.

\section{Notes}

The authors declare no competing financial interest.

\section{ACKNOWLEDGMENT}

This work was supported in part by the National Science Foundation (Grant No. DMR 13-07354) and the Office of Naval Research (Grant No. 0014-12-1-0828). M.J.R. gratefully acknowledges the Arnold and Mabel Beckman Foundation for a Beckman Institute Postdoctoral Fellowship.

\section{REFERENCES}

(1) (a) Caruso, M. M.; Davis, D. A.; Shen, Q.; Odom, S. A.; Sottos, N. R.; White, S. R.; Moore, J. S. Chem. Rev. 2009, 109, 5755-5798. (b) Li, J.; Nagamani, C.; Moore, J. S. Acc. Chem. Res. 2015, 48, 2181-2190. (c) Hickenboth, C. R.; Moore, J. S.; White, S. R.; Sottos, N. R.; Baudry, J.; Wilson, S. R. Nature 2007, 446, 423. (d) Black, A. L.; Lenhardt, J. M.; Craig, S. L. J. Mater. Chem. 2011, 21, 1655-1663. (e) Brantley, J. N.; Wiggins, K. M.; Bielawski, C. W. Polym. Int. 2013, 62, 2-12. (f) Li, M.; Zhang, Q.; Zhou, Y.-N.; Zhu, S. Prog. Polym. Sci. 2017. (2) (a) Chen, Y.; Spiering, A. J. H.; KarthikeyanS; Peters, G. W. M.; Meijer, E. W.; Sijbesma, R. P. Nat. Chem. 2012, 4, 559-562. (b) Davis, D. A.; Hamilton, A.; Yang, J.; Cremar, L. D.; Van Gough, D.; Potisek, S. L.; Ong, M. T.; Braun, P. V.; Martinez, T. J.; White, S. R.; Moore, J. S.; Sottos, N. R. Nature 2009, 459, 68-72. (c) Lee, C. K.; Beiermann, B. A.;
Macromolecules 2013, 46, 3746-3752. (d) Beiermann, B. A.; Kramer, S. L. B.; May, P. A.; Moore, J. S.; White, S. R.; Sottos, N. R. Adv. Funct. Mater. 2014, 24, 1529-1537. (e) Imato, K.; Irie, A.; Kosuge, T.; Ohishi, T.; Nishihara, M.; Takahara, A.; Otsuka, H. Angew. Chem. Int. Ed. 2015, 54, 6168-6172. (f) Robb, M. J.; Kim, T. A.; Halmes, A. J.; White, S. R.; Sottos, N. R.; Moore, J. S. J. Am. Chem. Soc. 2016, 138, 12328-12331. (3) Piermattei, A.; Karthikeyan, S.; Sijbesma, R. P. Nat. Chem. 2009, 1, 133-137.

(4) Ramirez, A. L.; Kean, Z. S.; Orlicki, J. A.; Champhekar, M.; Elsakr, S. M.; Krause, W. E.; Craig, S. L. Nat. Chem. 2013, 5, 757-761. (5) Larsen, M. B.; Boydston, A. J. J. Am. Chem. Soc. 2014, 136, 12761279.

(6) Chen, Z.; Mercer, J. A.; Zhu, X.; Romaniuk, J. A.; Pfattner, R.; Cegelski, L.; Martinez, T. J.; Burns, N. Z.; Xia, Y. Science 2017, 357, 475-479.

(7) (a) Potisek, S. L.; Davis, D. A.; Sottos, N. R.; White, S. R.; Moore, J. S. J. Am. Chem. Soc. 2007, 129, 13808-13809. (b) May, P. A.; Munaretto, N. F.; Hamoy, M. B.; Robb, M. J.; Moore, J. S. ACS Macro Lett. 2016, 5 , 177-180. (c) Robb, M. J.; Moore, J. S. J. Am. Chem. Soc. 2015, 137, 10946-10949. (d) Li, H.; Göstl, R.; Delgove, M.; Sweeck, J.; Zhang, Q.; Sijbesma, R. P.; Heuts, J. P. A. ACS Macro Lett. 2016, 5, 995-998. (e) Wang, L.-J.; Zhou, X.-J.; Zhang, X.-H.; Du, B.-Y. Macromolecules 2015, 49, 98-104.

(8) (a) Beiermann, B. A.; Davis, D. A.; Kramer, S. L. B.; Moore, J. S.;

Sottos, N. R.; White, S. R. J. Mater. Chem. 2011, 21, 8443. (b) Grady, M. E.; Beiermann, B. A.; Moore, J. S.; Sottos, N. R. ACS Appl. Mater. Interfaces 2014, 6, 5350-5355.

(9) (a) Klukovich, H. M.; Kouznetsova, T. B.; Kean, Z. S.; Lenhardt, J. M.; Craig, S. L. Nat. Chem. 2013, 5, 110-114. (b) Gossweiler, G. R.; Silberstein, M. N.; Wang, J.; Moore, J. S.; Sottos, N. R.; Braun, P. V.
Kouznetsova, T. B.; Craig, S. L. J. Am. Chem. Soc. 2015, 137, 6148-6151. (c) Wang, J.; Kouznetsova, T. B.; Craig, S. L. J. Am. Chem. Soc. 2016, 138, 10410-10412.

(10) (a) Li, J.; Shiraki, T.; Hu, B.; Wright, R. A.; Zhao, B.; Moore, J. S. J. Am. Chem. Soc. 2014, 136, 15925-15928. (b) Li, J.; Hu, B.; Yang, K.; Zhao, B.; Moore, J. S. ACS Macro Lett. 2016, 5, 819-822.

(11) Kosuge, T.; Imato, K.; Goseki, R.; Otsuka, H. Macromolecules 2016, 49, 5903-5911.

(12) Manivannan, M. S.; Silberstein, M. N. Extreme Mechanics Letters 2016, 8, 6-12.

(13) (a) Gupta, V.; Argon, A. S.; Parks, D. M.; Cornie, J. A. J. Mech. Phys. Solids 1992, 40, 141-180. (b) Yuan, J.; Gupta, V. J. Appl. Phys. 1993, 74, 2388-2396. (c) Wang, J. L.; Weaver, R. L.; Sottos, N. R. Exp. Mech. 2002, 42, 74-83. (d) Kitey, R.; Sottos, N. R.; Geubelle, P. H. Thin Solid Films 2010, 519, 337-344. (e) Grady, M. E.; Geubelle, P. H.; Braun, P. V.; Sottos, N. R. Langmuir 2014, 30, 11096-11102. (f) Yang, K.; Lee, J.; Sottos, N. R.; Moore, J. S. J. Am. Chem. Soc. 2015, 137, 16000-16003. (14) (a) Kandula, S. S. V.; Hartfield, C. D.; Geubelle, P. H.; Sottos, N. R. Thin Solid Films 2008, 516, 7627-7635. (b) Wang, J.; Weaver, R. L.; Sottos, N. R. Exp. Mech. 2002, 42, 74-83. (15) (a) Church, D. C.; Peterson, G. I.; Boydston, A. J. ACS Macro Lett. 2014, 3, 648-651. (b) Duan, H.-Y.; Wang, Y.-X.; Wang, L.-J.; Min, Y.-Q.; Zhang, X.-H.; Du, B.-Y. Macromolecules 2017, 50, 1353-1361. (16) Freund, L. B. Proc. Natl. Acad. Sci. U. S. A. 2009, 106, 8818-8823. (17) Tischer, T.; Rodriguez-Emmenegger, C.; Trouillet, V.; Welle, A.; Schueler, V.; Mueller, J. O.; Goldmann, A. S.; Brynda, E.; BarnerKowollik, C. Adv. Mater. 2014, 26, 4087-4092. 


\section{For Table of Contents Use Only}

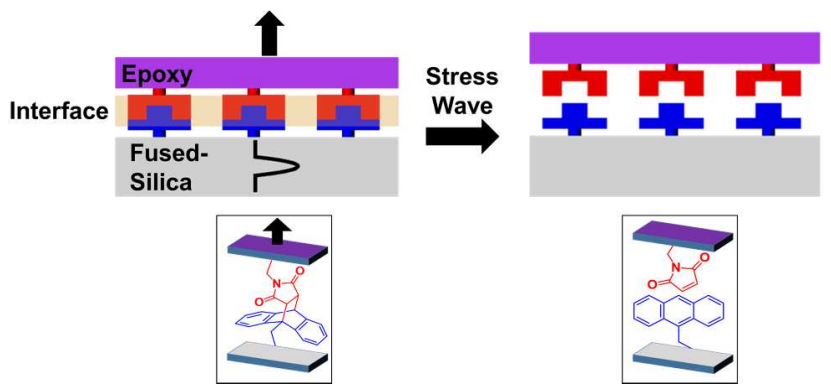

